\title{
Cancer Educational Materials
}

National Cancer Institute

\section{Source}

National Cancer Institute. Cancer Educational Materials. NCI Thesaurus. Code C19462.

Materials intended to educate the lay public in all aspects of cancer information 